\title{
Predicting Time Contingency in Construction Schedules for USACE Projects
}

\author{
Anoop Sattineni ${ }^{1}$, Anil Miglani ${ }^{2}$ and Lauren Redden ${ }^{1}$
}

1 Auburn University, Auburn, USA

2 United States Army Corps of Engineers, Washington, USA

\begin{abstract}
'Time Contingency' in construction planning is an often overlooked aspect and little attention is devoted to it during contract negotiations. There is lot of research done on cost contingencies in construction. This is especially true in Army or DOD projects even where construction completion is very critical to the mission. However, little research exists in the way of contingencies for construction schedule delays. In this paper researchers attempt to find various reasons for delay in USACE projects. Number of days are added to the construction schedule for past projects is analyzed and later used in Monte Carlo Simulation to predict the contingency time that can be added to the projects. As such, the objectives of the research presented in this paper are to assess the factors that affect scheduling contingency and to develop a simple model that can be used in estimating the expected time contingency of a construction project. Data was collected from USACE database of 80 projects and found that 26 of those were delayed because of various reasons. A total of 40 different reasons of delay were found in those 26 projects researched. These 40 different reasons were further grouped into 7 major categories to create a simple model using @Risk and Monte Carlo Simulation to predict time contingency. The model predicted a $10 \%$ time contingency for USACE projects which was very close to the observed schedule delays on sample projects.
\end{abstract}

(c) 2020 The Authors. Published by Budapest University of Technology and Economics \& Diamond Congress Ltd Peer-review under responsibility of the Scientific Committee of the Creative Construction Conference 2020.

Keywords: contingency, Monte Carlo simulation, schedule delays, USACE

\section{Introduction}

The Success and Failure of any project is determined mostly by three elements Cost, Quality and time. Delays are a very common feature in Construction. Results of various studies suggest main causes of delay in construction can be attributed to Designers, User changes, weather, changed site conditions, delays in financial condition, payments for completed work and material deliveries [1]. All these factors lead to construction claims, disputes and ultimately cost a lot of money to the stakeholders. The United States Army Corps of Engineers (USACE) manages hundreds for construction projects worldwide and several of their projects are delayed and delivered after the initial contract completion date. These delays are caused by various reasons like different site conditions, financial approvals, errors by architect/engineer (A/E), contaminated soils etc. Presently all the project's completion dates are derived either from the time needs by the client or the historical data on the similar projects. The biggest question is how do we calculate the construction completion date? Are we accounting the activities which might delay the project in calculating the completion dates of the project? The aim of this research is to investigate the reasons for delay in USACE Alaska district projects and create a model using Monte Carlo simulation for predicting the 'Time Contingency' for USACE construction projects.

Construction delays are very common in a project's construction lifespan. Even with the advanced technology available to us and project management techniques, construction projects are delayed and 
project completion dates shift accordingly. There are many reasons for these delays including labor strikes, rework, poor organization, material short-age, equipment failure, change orders, act of God etc. In addition, all the delays are inter often connected and their relation is complicated and generally triggered by delay in one or two schedule activities. Even though the construction schedule has got a lot of attention from researchers, very little has been seen in the field of 'Time Contingency', especially is the USACE projects. All of USACE projects have a 'Cost Contingency' in the project budget and a line item for time contingency is not seen and adding a line item for 'Time Contingency' could give USACE further assurance to help in managing expectations of the client.

\section{Literature review}

A review of literature was conducted to understand underlying issues related to construction schedule delays and their impact on projects.

\subsection{Construction delays}

Construction delays is a worldwide phenomenon and is one of the most common problems in construction projects. It is also usually the most expensive and complex problem to solve due to domino effects related to construction schedules. Since the delays affect both the owner and the contractor, it is a main reason for disputes and claims leading to lawsuits. To mitigate this problem a construction contract is created and followed to avoid these lawsuits and claims. Various numbers of 'General Condition Clause' are included in the contract to address site specific issues. Contract law defines various concepts of reasonableness and fair business practices such as warranties, responsibilities etc. A general understanding of the concepts and applicable clauses involved are essential to help make right decisions and to take the appropriate action in those construction delay situations [2]. Usually delays don't happen because of one single event, they develop slowly during the course of construction. Smaller delays are usually overlooked until their cumulative effect starts to affect the overall schedule, thereby impacting the project budget. By the time contractor recognizes that there is a problem, many other activities start to see the impact and resulting in moving the project completion date [3].

For a construction project to be successful, project must complete on time, within the budget, and within the required quality parameters. These three goals are intertwined with each other and affect each other. To complete a project on time, an accurate construction schedule must be created. Every project is unique, time contingency and cost uncertainties are essential for an accurate schedule, which must be flexible enough to accommodate changes without negatively affecting the overall duration of the project. It is important to allow a contingency value to both cost and time [4]. Yet, there are situations where the delays are unavoidable in activities that result in a delay in the overall project duration. Therefore, an estimate of time contingency is a major factor for achieving successful project completion. Every estimate / Schedule seen at USACE always have a contingency for money, but not for time. Therefore, the objective of the presented research in this paper is to identify the factors that affect (time) contingency and develop a simple model that forecast the expected contingency of a construction project.

\subsection{Contingency}

It is well known that the construction completion date is often missed due to uncertain events, and their impacts were difficult to predict because every construction project is unique [5]. Contingency, as Patrascu, A. [1] defines in his book means different things to different people. To management, it hopes all the money will not be expended and is sitting in an account and will be returned at the end of project. Contingency may become profit for the contractor if they run an effective cost control program. For an Engineer it could be a savings account which can be used to cover the additional cost of underestimated or not-included-inbudget construction activities.

The contractor's contingency is represented by a fixed percentage of the contract value or percentage of total project cost or duration [4]. Touran [4] suggest two values of cost contingency: (1) $15 \%$ for underground construction activities and tunnelling and (2) 7.5\% for the rest of the project. Others suggest time contingency to be used to assure the completion time of a project and provide a degree of confidence 
that the planned duration can be accomplished successfully [6]. Researchers have focussed efforts to consider Monte Carlo simulations to predict an appropriate time contingency [7], [8]. Monte Carlo simulation is a computerized mathematical technique that allows one to account for risk in analysis and decision making.

\section{Research methodology}

A mixed method research methodology was used in the conduct of this research. Archival data for a sample 80 construction projects was retrieved from the Alaska district's Resident Management System (RMS). RMS documents additional costs and time added to a project from the initial estimate and schedule respectively. This data was used to identify 26 projects that were delayed and as the records indicated a growth in schedule increases. The project managers / engineers for these projects were interviewed to understand factors influencing of time growth. These factors were used to generate Monte Carlo simulations to predict time contingency on construction projects.

\section{Results}

USACE maintains all construction project related data in RMS. This data was used to analyse data for 80 projects between 2017 and 2020 . The projects ranged from $\$ 300,000$ to $\$ 37$ million. Of the projects considered, 26 of them were found to have time delays, as shown in Table 1. The percentage growth in schedules were seen from $1.3 \%$ to nearly $300 \%$. The project managers for these projects were interviewed to understand issues related to the cause of these delays.

Table 1: Cost and time growth data for projects

\begin{tabular}{|c|c|c|c|}
\hline Project Cost & Original Duration (Days) & Time Growth - Days & Time growth in \% \\
\hline$\$ 3,737,838$ & 363 & 1,051 & $289.50 \%$ \\
\hline$\$ 3,176,500$ & 947 & 50 & $5.30 \%$ \\
\hline$\$ 19,754,000$ & 636 & 176 & $27.70 \%$ \\
\hline$\$ 7,841,500$ & 581 & 618 & $106.40 \%$ \\
\hline$\$ 37,260,400$ & 757 & 99 & $\$ 0.13$ \\
\hline$\$ 11,836,000$ & 450 & 53 & $11.80 \%$ \\
\hline$\$ 20,132,323$ & 519 & 123 & $23.70 \%$ \\
\hline$\$ 34,040,000$ & 610 & 14 & $2.30 \%$ \\
\hline$\$ 22,333,348$ & 540 & 153 & $28.30 \%$ \\
\hline$\$ 12,177,483$ & 495 & 33 & $6.70 \%$ \\
\hline$\$ 13,291,429$ & 450 & 81 & $18.00 \%$ \\
\hline$\$ 9,898,068$ & 661 & 8 & $1.20 \%$ \\
\hline$\$ 19,051,000$ & 680 & 179 & $26.30 \%$ \\
\hline$\$ 33,061,944$ & 720 & 128 & $17.80 \%$ \\
\hline$\$ 4,094,093$ & 177 & 15 & $8.50 \%$ \\
\hline$\$ 975,340$ & 27 & 37 & $137.00 \%$ \\
\hline$\$ 361,995$ & 284 & 30 & $10.60 \%$ \\
\hline$\$ 5,497,904$ & 50 & 8 & $16.00 \%$ \\
\hline$\$ 8,192,750$ & 730 & 76 & $10.40 \%$ \\
\hline$\$ 9,525,000$ & 54 & 3 & $5.60 \%$ \\
\hline$\$ 5,744,964$ & 639 & 102 & $16.00 \%$ \\
\hline$\$ 663,076$ & 79 & 45 & $57.00 \%$ \\
\hline$\$ 847,820$ & 233 & 16 & $6.90 \%$ \\
\hline$\$ 33,192,500$ & 575 & 257 & $44.70 \%$ \\
\hline$\$ 2,263,812$ & 142 & 73 & $51.40 \%$ \\
\hline$\$ 19,278,001$ & 794 & 10 & $1.30 \%$ \\
\hline
\end{tabular}


The responses to the delays were broadly categorized under seven themes, from 40 reasons that project managers identified as the cause of those delays. The 40 responses from the interviews highlighting the causes of delay are shown in Figure 1 below.

\begin{tabular}{|c|c|}
\hline $\begin{array}{l}\text { No. of days } \\
\text { added to the } \\
\text { schedule }\end{array}$ & Reasons for Delay \\
\hline 1051 & Environmental Management plan / Dewatering permission \\
\hline 50 & Funding Issues \\
\hline 84 & contaminated soil \\
\hline 49 & Design Conflicts \\
\hline 30 & Client requested Changes \\
\hline 13 & Move detectors - Discrepency in Drawings \\
\hline 618 & Perfafrost - unsuitable site Conditions \\
\hline 21 & Fire protection system - Revised \\
\hline 20 & Lift station size increase \\
\hline 58 & Building Enclosure \\
\hline 53 & Different site conditions \\
\hline 15 & Interior ? Exterior Building Conditions \\
\hline 108 & User requested Changes \\
\hline 14 & Drawing Conflicts \\
\hline 153 & Door detection system - Specification issues \\
\hline 33 & Cercla - Contaminated soil disposal \\
\hline 81 & Foam generator location - Design conflicts \\
\hline 35 & Drawings Conflicts \\
\hline 8 & Adding an additional Fire wall - Design conflicts \\
\hline 179 & Contaminated soil changes \\
\hline 85 & HVAC design Issued \\
\hline 38 & Lead Casing Bullets found in soil - Contaminated soil \\
\hline 5 & User request Change- Reprograming security system \\
\hline 15 & RFP not clear \\
\hline 300 & Design Inadequate \\
\hline 70 & Funding \\
\hline 30 & Specs / Drawing Conflicts \\
\hline 50 & User requested changes \\
\hline 30 & Funding \\
\hline 76 & Drawings Conflicts \\
\hline 30 & Asbestos removal - pipes \\
\hline 50 & Contractor posseion of site delayed by user \\
\hline 41 & Additional scope - Doors replacement \\
\hline 10 & Hidden site conditions \\
\hline 45 & unforseen weather conditions \\
\hline 16 & Additional scope added after the removal of Hood \\
\hline 257 & $A D E C / E P A$ requirements \\
\hline 42 & Clreaence to construct delays - User Issues \\
\hline 25 & Design issues \\
\hline 10 & Adminstratived delays \\
\hline
\end{tabular}

Figure 1: Interview data showing causes of delays

A sample of the data collected through the interviews and the frequency of occurrence of each of the themes is shown in Figure 1.

- Administrative

- Design Related

- Regulatory

- Funding

- Additional scope

- Different site conditions

- Unforeseen Weather 
The frequency of occurrence of each of themes and their percentages was calculated and shown in Figure 2.

\begin{tabular}{|c|c|c|}
\hline Unforeseen weather & 1 & $3 \%$ \\
\hline Administrative Related & 4 & $10 \%$ \\
\hline Design Related & 15 & $38 \%$ \\
\hline Regulatory Delays & 2 & $5 \%$ \\
\hline Funding Related & 3 & $8 \%$ \\
\hline User requested - Additional scope & 6 & $15 \%$ \\
\hline Different Site Conditions & 9 & $23 \%$ \\
\hline
\end{tabular}

Figure 2: Frequency of Delay Occurrence and Percentages

The data collected was used to determine weightage or probability of a theme occurring on a project based on the occurrence of these 26 projects, as shown in Table 2.

Table 2: Time Growth in Percentage and Weightage for Monte Carlo Simulation

\begin{tabular}{|c|c|c|c|c|c|c|c|}
\hline & Administrative & $\begin{array}{l}\text { Design } \\
\text { Related }\end{array}$ & Regulatory & Funding & $\begin{array}{l}\text { Additional } \\
\text { scope }\end{array}$ & $\begin{array}{l}\text { Different } \\
\text { site } \\
\text { conditions }\end{array}$ & $\begin{array}{c}\text { Unforeseen } \\
\text { Weather }\end{array}$ \\
\hline & 8 & 8 & 289 & 5 & 5 & 13 & 57 \\
\hline & 8 & 2 & 45 & 26 & 21 & 106 & \\
\hline & 30 & 3 & & 6 & 1 & 12 & \\
\hline & 2 & 3 & & & 10 & 3 & \\
\hline & & 2 & & & 6 & 7 & \\
\hline & & 28 & & & 7 & 26 & \\
\hline & & 18 & & & & 5 & \\
\hline & & 10 & & & & 6 & \\
\hline & & 1 & & & & 2 & \\
\hline & & 12 & & & & & \\
\hline & & 9 & & & & & \\
\hline & & 111 & & & & & \\
\hline & & 11 & & & & & \\
\hline & & 10 & & & & & \\
\hline & & 10 & & & & & \\
\hline Average & 12 & 16 & 167 & 12 & 8 & 20 & 57 \\
\hline Weightage & 1 & 3.8 & 0.5 & 0.8 & 1.5 & 2.3 & 0.3 \\
\hline
\end{tabular}

A software program named '@Risk' was used to conduct the Monte Carlo simulation. A summary of the process and related results are discussed here.

- Calculate the average $\%$ of days added to the schedule.

- Assign the weights to the categories, reasons of delay based on the occurrence. The weights are based on the probability divided by 10 .

- Multiply the weights by the average no of days added to the project.

- This total is the maximum most likely days added to the schedule.

- This number is used in the @Risk Calculations for calculating the 'Time Contingency' for the construction schedule showing the @ Risk spreadsheet calculations.

- After running the simulation we see the simulation predicts the time contingency of $10 \%$ should be added to the Construction schedule with the 95\% probability, as shown in Figure 3. 


\begin{tabular}{|c|c|c|c|c|c|c|c|c|}
\hline Activities affecting the Schedule & Base Case & imum & Most Likely & Maximum & Minimum & Most Likely & Maximum & Sampled \\
\hline Administrative & 10 & $99 \%$ & $100 \%$ & $112 \%$ & 10 & 10 & 11 & 10 \\
\hline Design Related & 10 & $99 \%$ & $100 \%$ & $162 \%$ & 10 & 10 & 16 & 11 \\
\hline Regulatory & 10 & $99 \%$ & $100 \%$ & $184 \%$ & 10 & 10 & 18 & 11 \\
\hline Funding & 10 & $99 \%$ & $100 \%$ & $110 \%$ & 10 & 10 & 11 & 10 \\
\hline Additional Scope & 10 & $99 \%$ & $100 \%$ & $113 \%$ & 9.9 & 10 & 11 & 10 \\
\hline Different site conditions & 10 & $99 \%$ & $100 \%$ & $146 \%$ & 9.9 & 10 & 14.6 & 10.75 \\
\hline \multirow[t]{2}{*}{ Unforseen Conditions } & 10 & $99 \%$ & $100 \%$ & $117 \%$ & 10 & 10 & 12 & 10 \\
\hline & & & & & 0 & 0 & 0 & 0 \\
\hline \multicolumn{9}{|l|}{ Output } \\
\hline Totals & 70 & & & & & & & \\
\hline \multicolumn{9}{|l|}{ Summary statistics } \\
\hline Probability of meeting base case value & $95.00 \%$ & & & & & & & \\
\hline Time required for $95.0 \%$ confidence & 77 & & & & & & & \\
\hline Contingency required for $95.0 \%$ confidence & 7 & $10 \%$ & & & & & & \\
\hline
\end{tabular}

Figure 3: @Risk spreadsheet showing the calculations for Time contingency, using Monte Carlo Simulation

Figure 3 above shows the number of days added to the construction schedule in percentage. The results show that the $10 \%-13 \%$ of time was added to the schedule in 29 projects, $14 \%-20 \%$ of the time was added to 2 projects, and $20 \%$ or more of the time was added to balance 9 projects.

\section{Conclusions}

Looking at the results from risk model we can see that the model is suggesting a $10 \%$ Time contingency for the USACE projects, which is close to the results from our manual calculations which shows that $72 \%$ of the projects extended $10 \%-13 \%$ of time to the projects. This sample suggests that the model can be used to predict the time contingency to the construction projects. The variables in this model are the probability of occurrence and based on the location and region for the projects. Thus, using this type of model can be very useful in predicting the 'Time Contingency' we can add to the construction schedule. Future research may include running similar models in each of the USACE districts to explore trends. This could help USACE administrators understand regional and national trends as related to time contingencies.

\section{References}

[1] Patrascu, A. (1988). "Construction Cost Engineering Handbook," CRC Press. https://www.routledge.com/Construction-CostEngineering-Handbook/Patrascu/p/book/9780824778279 (accessed May 25, 2020). M. Dekker, New York, USA.

[2] Assaf Sadi A., Al-Khalil Mohammed, and Al-Hazmi Muhammad, "Causes of Delay in Large Building Construction Projects," Journal of Management in Engineering, vol. 11, no. 2, pp. 45-50, Mar. 1995, https://doi.org/10.1061/(ASCE)0742-597X(1995)11:2(45).

[3] D. E. Hancher and J. E. Rowings, "Setting Highway Construction Contract Duration," Journal of the Construction Division, vol. 107, no. 2, pp. 169-179, 1981.

[4] Touran Ali, "Probabilistic Model for Cost Contingency," Journal of Construction Engineering and Management, vol. 129, no. 3, pp. 280-284, Jun. 2003, https://doi.org/10.1061/(ASCE)0733-9364(2003)129:3(280).

[5] John Perry and Peter Thompson, Engineering Construction Risks - A Guide to Project Risk Analysis and Risk Management. Thomas Telford Ltd, 1992.

[6] Park Moonseo and Peña-Mora Feniosky, "Reliability Buffering for Construction Projects," Journal of Construction Engineering and Management, vol. 130, no. 5, pp. 626-637, Oct. 2004, https://doi.org/10.1061/(ASCE)0733-9364(2004)130:5(626).

[7] Hazem Yahia, Hossam Hosny and Mohammad E. Abdel Razik, (2011). "Time Contingency Assessment in Construction Projects in Egypt using Artificial Neural Networks Model" IJCSI International Journal of Computer Science Issues, Vol. 8, Issue 4, No 2.

[8] N. D. Boskers and S. M. AbouRizk, "Modeling scheduling uncertainty in capital construction projects," in Proceedings of the Winter Simulation Conference, 2005., Dec. 2005, pp. 8 pp.-, https://doi.org/10.1109/WSC.2005.1574417. 